\title{
Detection of Numerous Verotoxigenic E. Coli Serotypes, with Multiple Antibiotic Resistance from Cattle Faeces and Soil
}

\author{
L. Scott \\ Kildare, Ireland \\ P. McGee \\ Teagasc, Ashtown Food Research Centre, Dublin, Ireland \\ Ciara Walsh \\ Technological University Dublin, ciara.walsh@tudublin.ie
}

Veterinary Laboratory Services, Department of Agriculture, Fisheries and Food, Backweston Complex, Co

See next page for additional authors

Follow this and additional works at: https://arrow.tudublin.ie/schfsehart

Part of the Food Science Commons

\section{Recommended Citation}

Scott, L., Walsh, C. et al (2009) Detection of numerous verotoxigenic E. coli serotypes, with multiple antibiotic resistance from cattle faeces and soil. Veterinary microbiology, 134,288-293 doi.org/10.1016/ j.vetmic.2008.08.008

This Article is brought to you for free and open access by the School of Food Science and Environmental Health at ARROW@TU Dublin. It has been accepted for inclusion in Articles by an authorized administrator of ARROW@TU Dublin. For more information, please contact arrow.admin@tudublin.ie, aisling.coyne@tudublin.ie, gerard.connolly@tudublin.ie.

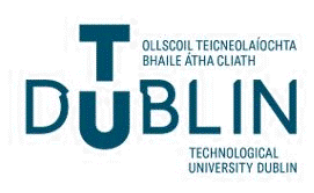


Authors

L. Scott, P. McGee, Ciara Walsh, Seamus Fanning, T. Sweeney, J. Blanco, M. Karczmarczyk, B. Earley, N. Leonard, and J.J. Sheridan

This article is available at ARROW@TU Dublin: https://arrow.tudublin.ie/schfsehart/259 
$1 \quad$ Running Title: Numerous antibiotic resistant VTEC isolated in faeces and soil

2 Detection of numerous verotoxigenic $E$. coli serotypes, with multiple antibiotic

3 resistance from cattle faeces and soil

4 L. Scott ${ }^{1}{ }^{2 *}$ P. McGee ${ }^{2}$, C. Walsh ${ }^{3}$, S. Fanning ${ }^{3}$, T. Sweeney ${ }^{4}$, J. Blanco ${ }^{5}, \mathrm{M}$

5 Karczmarczyk $^{3}$, B. Earley ${ }^{6}$, N. Leonard ${ }^{7}$, J.J. Sheridan ${ }^{2}$.

6

7

${ }^{1}$ Veterinary Laboratory Services, Department of Agriculture, Fisheries and Food, Backweston Complex, Co Kildare, Ireland, ${ }^{2}$ Teagasc, Ashtown Food Research Centre, Dublin, Ireland, ${ }^{3}$ Centre for Food Safety, School of Agriculture, Food Science and Veterinary Medicine, University College Dublin, Ireland, ${ }^{4}$ Animal Husbandry and Production, School of Agriculture, Food Science and Veterinary Medicine, University College Dublin, Ireland, ${ }^{5}$ E. coli Reference Laboratory (LERC), Faculty of Veterinary Medicine, University of Santiago de Compostela, Lugo, Spain, ${ }^{6}$ Teagasc, Grange Research Centre, Co. Meath, Ireland, Veterinary Microbiology and Parasitology, ${ }^{7}$ School of Agriculture, Food Science and Veterinary Medicine, University College Dublin, Ireland,

* Corresponding author: Telephone 353-1-6157352, Fax 3531 6157353 Email: lourda.scott@agriculture.gov.ie

\section{Abstract}

18 Verotoxigenic E. coli (VTEC) belong to a diverse range of serotypes. Serotypes O157 and O26 are predominately identified in VTEC-associated disease in Europe, however due to difficulty in detection little is known about the epidemiology of non-O157 serotypes. This study reports the identification of 7 VTEC serotypes from cattle faeces and soil. Cattle faeces samples $(n=128)$ were taken from animals in 6 different farms, with soil samples $(n=20)$ obtained from one farm. After sample incubation in modified tryptone soy broth (mTSB) supplemented with streptomycin sulphate samples were plated onto sorbitol MacConkey (SMAC) also supplemented with streptomycin sulphate. Bacteria detected on the plates were subjected to biochemical testing, antibiotic resistance profiling, and PCR to detect typical

27 virulence genes, $B$ lactamase and Class 1 Integron associated genes. Serotyping was 
1 with verotoxin genes present in $7 \mathrm{E}$. coli isolates. Of these 7 isolates, 5 were resistant to five 2 or more antibiotics. The isolate resistant to 9 antimicrobials contained a Class 1 Integron 3 structure. Serotyping identified 7 separate VTEC, O2:H27, O26:H11, O63:H-, O148:H8, 4 O149:H1, O174:H21 and ONT:H25. Six of these VTEC have been previously associated 5 with human disease, however with the exception of O26:H11, these serotypes have been 6 rarely reported worldwide. Increased surveillance is required to determine the prevalence of 7 these and other non-O157 VTEC. The presence of multi-antibiotic resistance in these isolates 8 is of concern, and the overall implications for public health must be ascertained.

9

10

11

12

13

14

15

16

17

18

19

20

21

22

23 


\section{1. Introduction}

2 Since the emergence of verotoxigenic E. coli (VTEC) as human pathogens, contamination of

3 foods of animal origin has been a major public health concern. Cattle are considered the

4 main reservoir of VTEC, with infection associated with the consumption of contaminated

5 beef and beef products (Griffin and Tauxe, 1991, Elder et al., 2000) or direct contact with

6 animals and animal faeces on the farm (Howie et al., 2003, Crump et al., 2003). VTEC can

7 produce severe illness in humans, leading to this infection being listed as a notifable disease

8 in all European countries (EU-Report, 2001, Sanco 2001). The virulence of VTEC can be

9 characterized by the expression of genes for potent verotoxins (VT1 and VT2), genes for

10 intimin production (eae), and hly gene. (Frankel et al., 1998, Donnenberg et al., 2001).

11 In the US, Canada, United Kingdom and Japan, serotype O157 is predominately

12 identified in VTEC-associated disease. Unlike other E. coli serotypes, VTEC O157:H7 do

13 not ferment sorbitol and are $\beta$-glucuronidase negative. These unique properties make the

14 identification of this strain on selective media, such as sorbitol MacConkey (SMAC),

15 straightforward (Mora et al., 2004). Infections with strains from serogroups such as O26,

$16 \mathrm{O} 111, \mathrm{O} 103$ and $\mathrm{O} 145$ are the most common non-O157 VTEC associated with illness in

17 humans (Blanco et al., 2004a). However, non-O157 VTEC infections may be frequently

18 overlooked as they are indistinguishable from normal intestinal coliforms on the routinely

19 used SMAC. Information on the source of non-O157 VTEC strains and their potential role in

20 human disease is thus limited and needs further examination.

21 The present study compares the phenotypic and genotypic characteristics of unusual

22 non-O157 VTEC strains, which were isolated from healthy cattle and soil. 


\section{2. Materials and Methods}

\section{$2 \quad 2.1$ Isolation and Identification of Isolates}

\section{2.1.1 Collection of samples}

4 Faeces and soil samples were collected from 6 unrelated farms in the months of July to

5 November. One faeces sample $(10 \mathrm{~g})$ was taken from the rectum of each animal $(\mathrm{n}=108)$

6 while soil samples (20 g), were obtained once from 5 paddocks on the same farm $(\mathrm{n}=20)$.

7 Each animal was sampled once. In accordance with EU regulations, none of the animals was

8 given food that contained anti-microbial agents. The soil samples were obtained from

9 paddocks, which were empty of cattle at the time of sampling, although they had been grazed

10 previously. There was no known contact of personnel or animals between the farms.

\section{$12 \quad$ 2.1.2 Enrichment of samples}

13 Faeces samples were enriched in mTSB broth, (Oxoid, UK) containing streptomycin

14 sulphate $(1000 \mu \mathrm{g} / \mathrm{ml})$ stomached in a Colworth Stomacher (Model BA 6024, A. J. Steward

15 \& Co.Ltd. London, UK), and incubated at $37^{\circ} \mathrm{C}$ for $24 \mathrm{~h}$. Aliquots were plated onto sorbitol

16 MacConkey agar (Oxoid, UK) containing streptomycin sulphate (1000 $\mu \mathrm{g} / \mathrm{ml})$, (SMAC-

17 strep), and incubated at $37^{\circ} \mathrm{C}$ for $24 \mathrm{~h}$. Following incubation, a single colony was taken from

18 each sample and stored on cryoprotective beads at $-20^{\circ} \mathrm{C}$ until required for biochemical and

19 molecular testing (Protect, Technical Services Consultants, Lancashire, UK). The presence

20 of any bacterial growth on the plates after enrichment was considered a positive sample. 


\section{$1 \quad 2.1 .3$ Phenotypic characterisation}

2 Each isolate was Gram stained and characterized using API 20E and API 50CH commercial

3 kits according to manufacturers instructions (Biomerieux).

\section{$5 \quad$ 2.1.4 Virulence determination}

6 After resuscitation from storage beads, template DNA was prepared from a single colony of

7 each isolate. DNA was purified from the culture with a DNeasy extraction kit (Qiagen,

8 Crawley, UK). All isolates were screened for virulence factors commonly associated with

9 VTEC, eae, hly, vt 1 and $v t 2$ genes using a multiplex PCR method (Paton and Paton, 1998).

10 The presence of virulence genes was also confirmed by independent PCR analysis by the

11 Laboratorio de Referencia de E. coli (LREC, Lugo, Spain) (Blanco et al., 2004b). Isolates

12 positive for one or more of these genes were also screened for the presence of the $r f b_{0157}$

13 gene (Paton and Paton, 1998) and $f l i C_{\mathrm{h} 7}$ gene (Fratamico et al., 2000). PCR products were

14 separated by electrophoresis on a $2 \%$ agarose gel, stained with ethidium bromide and

15 visualised under UV illumination. The PCR products of eaeA, hly, vt 1 and $v t 2$ genes were

16 purified using a PCR purification kit (Nucleospin Extract 11, Machery-Nagel, Germany) and

17 sequenced commercially in duplicate (MWG Biotech, Ebersberg, Germany). Sequences were

18 initially compared with the current GenBank sequence databases using the BLAST suite of

19 programs (Altschul et al., 1997). ClustalW amino acid sequence alignments were produced

20 for comparison online at http://www.ebi.ac.uk/clustalw. 


\section{$1 \quad 2.1 .5$ Toxin production}

2 Isolates positive for $v t 1$ or $v t 2$ genes following PCR were tested for verotoxin production,

3 using the commercial ELISA Premier-VTEC kit according to the manufacturers instructions

4 (Meridian, Bioscience).

5

\section{$6 \quad$ 2.1.6 Serotyping}

7 Serotyping was performed on isolates positive for virulence genes. The determination of $\mathrm{O}$ 8 and $\mathrm{H}$ antigens was carried out by the LREC, (Lugo, Spain) as previously described, (Guinée 9 et al., 1981) employing all available $\mathrm{O}(\mathrm{O} 1-\mathrm{O} 185)$ and $\mathrm{H}(\mathrm{H} 1-\mathrm{H} 56)$ antisera. All antisera 10 were obtained and absorbed with the corresponding cross-reacting antigens to remove the 11 nonspecific agglutinins. The $\mathrm{O}$ antisera were produced in the LERC and the $\mathrm{H}$ antisera were 12 obtained from the Statens Serum Institute (Copenhagen, Denmark).

\section{$13 \quad 2.2$ Antibiotic susceptibility testing}

\subsubsection{Phenotypic characterisation}

Isolates positive for virulence genes, were examined for susceptibility to 12 antibiotics using the Bauer - Kirby disc diffusion method (Bauer et al., 1966). The following discs (Oxoid, U.

$18 \mathrm{~K}$.) were used: ampicillin $10 \mu \mathrm{g}$, kanamycin $30 \mu \mathrm{g}$, cefixime $5 \mu \mathrm{g}$, cefaclor $30 \mu \mathrm{g}$, streptomycin

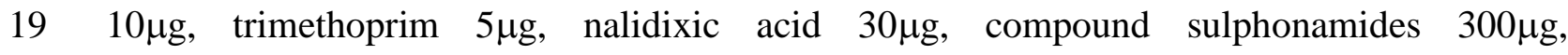

20 chloramphenicol $30 \mu \mathrm{g}$, tetracycline $30 \mu \mathrm{g}$, ciprofloxacin $5 \mu \mathrm{g}$ and moxalactam $30 \mu \mathrm{g}$. . E coli

21 strain ATCC 25922 and S. aureus strain ATCC 25923 were used for quality control. (Oxoid,

22 UK). After incubation, the diameter (in millimeters) of the zone of inhibition of each

23 antibiotic was measured. Isolates were classed as sensitive or resistant to each antibiotic

24 according to Committee for Laboratory Standards Institute (CLSI) guidelines (NCCLS, 25 2003). 


\section{$1 \quad 2.2 .2 \beta$-lactamase and Class 1 Integron associated genes}

2 Template DNA from seven serotyped isolates was examined by PCR for several $\beta$-lactamase

3 (bla) encoding genes including; tem, carb, shv, oxa and ctx, as described previously

4 (Wichard, 2005; Henriques et al. 2006; Batchelor et al. 2005, Pomba et al. 2006). Variable

5 regions containing the gene cassette(s) associated with class 1 integron structures were

6 amplified, as described previously (O'Mahony et al. 2005). The genes mapping to the 5'-

7 and 3'-conserved structures of class 1 integrons, were also identified by PCR.

\section{2.2.3 DNA sequence analysis of Gene Cassettes}

10 Amplicons of interest were extracted directly from agarose gels using a QIAGEN gel 11 extraction kit (QIAGEN, West Sussex, UK). The recovered DNA fragment of interest was 12 purified and quantified (as described above) prior to being sequenced commercially (Qiagen,

13 Hilden, Germany). Sequence text files were subsequently obtained and used to search the 14 current GenBank databases using the BLAST suite of programs (Altschul et al., 1997).

15 CLUSTALW amino acid sequence alignments were produced for comparison (Thompson et 16 al., 1994).

\section{3. Results}

20 From 128 samples collected, 103 isolates were obtained which grew on SMAC-strep, 21 covering the plate with a sorbitol fermenting (pink), mucoid growth. Each sample was 22 individually sub-cultured onto SMAC-strep from which a single colony was taken for 23 subsequent testing. Upon subculturing, large ( $2 \mathrm{~mm}$ diameter), round, mucoid colonies were 24 observed and Gram-negative rod-shaped bacteria were identified following staining. All 
1 isolates were negative for Voges-Proskaur, hydrogen sulfide, citrate, oxidase and urease

2 production and were positive for indole and fermented glucose, mannitol and sorbitol. The

3 isolates were confirmed as E. coli following analysis of API 20E and API 50CH strip results.

4 The API results were confirmed by PCR amplification of the 16S rRNA gene (data not 5 shown).

\subsection{Virulence determination}

7 From the 103 E. coli isolates tested, 7 were positive for the presence of $v t 1$ or $v t 2$ genes as

8 presented in Table 1. Of these isolates, 4 were detected from cattle in Farm A, one from soil

9 in Farm A and 2 isolates were detected from cattle faeces taken in Farms B and D. All 7

10 isolates were negative for the presence of the $r f b_{\mathrm{O} 157}$ and $f l i C_{\mathrm{h} 7}$ genes. Two isolates of were

11 also identified positive for the presence of eae and hly genes. Both isolates were serotyped

12 as $\mathrm{O} 123: \mathrm{H} 2$. However as these isolate did not contain $v t$ gene they are not included in the

13 data presented in this paper.

\section{$14 \quad 3.2$ PCR product sequencing}

15 Isolates obtained from animals 92 and 80 were not included in the PCR product sequencing 16 analysis as either the $v t 1$ gene was lost following storage (isolate 92) or the isolate could not

17 be resuscitated (isolate 80). BLAST searches showed that PCR products from positive $v t 1$,

$18 v t 2$, hly and eaeA reactions were homologus to similar sequences in known bacteria carrying

19 these genes. Deduced amino acid sequences from each PCR product were compared with

20 selected known bacteria using ClustalW. The alignment demonstrated a similar amino acid

21 homology across the regions examined. In summary it can be stated that the genes for vtl, $22 v t 2$, eae and hly were present in the isolates examined. 


\subsection{Verotoxin production}

2 Verotoxin production was confirmed for each isolate positive for the presence of $v t 1$ or $v t 2$ 3 gene.

\section{$4 \quad 3.4$ Serotyping}

$5 \quad$ Serotyping was performed and 7 different VTEC serotypes were identified; O2:H27,

6 O149:H1, O26:H11, O63:H-, O148:H8 and O174:H25 with one untypeable serotype 7 ONT:H25 (Table 1).

8

\section{$9 \quad 3.5$ Antibiotic susceptibility}

10 Multi drug resistance (the resistance to three or more different antibiotic classes) was

11 demonstrated in 5 of the 7 isolates. The AR profiles (Table 1) show that some of the isolates

12 share a common resistance pattern. Serotype O174:H21 obtained from Farm D was resistant

13 to the same 5 antibiotics as serotypes $\mathrm{O} 2: \mathrm{H} 27$ and $\mathrm{O} 26: \mathrm{H} 11$ isolated from Farm A.

\subsection{1 $\beta$-lactamase and Class 1 Integron associated genes}

16 The bla-TEM gene was present in all 7 of the VTEC isolates with the exception of isolate 50

17 and 84. None of the other bla genes tested were found to be present. E. coli $\mathrm{O} 63: \mathrm{H}-$ was the

18 only strain found to contain complete class 1 integron structures. The integrase1 (int1),

19 quaternary ammonium compound resistance (qacDE1), and sulphonamide resistance (sull)

20 genes in addition to 4 gene cassettes (of sizes including 1.0,1.2, $1.6 \mathrm{~kb}$ ) were detected after 21 PCR.

23 3.5. DNA sequence analysis of gene cassettes 
1 Sequence analysis of two gene cassettes $1.0 \mathrm{~kb}$ and $1.2 \mathrm{~kb}$ (Accession numbers EU 938126

2 and EU938125) amplified from the E. coli $\mathrm{O} 63: \mathrm{H}-$, gave $100 \%$ sequence identity to the

3 aadAl gene in E. coli. The remaining gene $1.6 \mathrm{~kb}$ gene cassette (Accession No. EU938127)

4 contained two ORF's in the classical 'head-to-tail' orientation, with complete identity to a

$5 d f r l$ gene and aadAl gene in E. coli. The aadAl (adenyltransferase) gene confers

6 aminoglycoside resistance and the $d f r$ (dihydrofolate reductase) gene confers trimethoprim

7 resistance.

8

9

10

11

12

13

14

15

16

17

18

19

20 


\section{4. Discussion}

2 This study reports on the isolation of multiple VTEC serotypes from cattle faeces and

3 soil. Of 103 antibiotic AR E. coli isolates in this study, 7 verotoxigenic serotypes, were

4 identified. To detect whether these VTEC had been previously reported, a reference list

5 was used which summarises published data on the serotypes and origin of non-O157

6 VTEC up to 2003 (www.microbionet.com.au/vtectable.htm), in addition to a list of

7 VTEC reported from the E. coli reference lab in Lugo, Spain

8 (http://www.lugo.usc.es/ecoli/). Comparison with these, suggest that the serotypes found

9 in the current study have been rarely reported previously, with the exception of O26:H11.

10 Serotype O63:H- has never been reported from any source.

11 In contrast to E. coli $\mathrm{O} 157: \mathrm{H} 7$, the identification of non-O157 VTEC is complex,

12 with no obvious characteristics to consistently distinguish them from other E. coli

13 serotypes.. In the present study, two of the seven serotypes detected, were obtained from

14 farms remote from each other, where just six and four animals were sampled. This is in

15 contrast to previous reports where extensive sampling and screening of multiple coliform

16 colonies were obtained in order to isolate different serotypes. Beutin et al. (1997),

17 examined 114 faeces samples from 19 cattle, and isolated 11 VTEC serotypes. In a

18 VTEC prevalence study in Japan, faecal samples were taken from 358 animals and 20

19 coliform colonies per sample were tested for $v t$ encoding genes, revealing 25 different

20 serotypes (Kobayashi et al., 2001).

21 In the present study all of the isolates fermented sorbitol and therefore would be

22 overlooked if non-sorbitol fermenting colonies only were selected, as is usual with

23 routine methods. The fact that these isolates are resistant to a number of anti-microbial 
1 agents may aid their detection in future studies by supplementing selective media with

2 the appropriate anti-microbials. It should be noted, however, that as the methodology in

3 the current study selected for streptomycin resistant VTEC only, a different protocol may

4 have detected additional, non AR VTEC isolates. The results from the current study

5 suggest that the prevalence and variety of non-O157 VTEC in food animals may be

6 grossly underestimated, with the lack of standardised methods leading to difficulty in

7 ascertaining the prevalence of these and other unidentified VTEC serotypes present in

8 cattle and the food chain.

9 The acquisition of verotoxin genes by enteric bacteria is well documented and the

10 horizontal transmission of virulence factors has been crucial to the emergence of VTEC

11 as important pathogens (Moxon et al., 1994). The isolates identified in this study

12 contained many virulence factors that are associated with human disease and serotypes

13 O2:H27, O149:H1, ONT:H25, O148:H8 and O174:H21 have been each been identified

14 as infrequent human pathogens from several countries in Europe and North America.

15 Verotoxin (VT) production was confirmed in just six of seven isolates as a $v t$ gene was

16 lost from serotype ONT:H25 following longterm storage (9 months). The loss of $v t$ gene-

17 carrying phages has been previously reported following storage and cultivation of E. coli

18 O157:H7 and non O157 isolates (Iguchi et al., 2002, Murase et al., 1999).

19 The production of VT2 alone is associated with more serious clinical disease

20 (Ostroff et al., 1989, Boerlin et al., 1999) and this toxin was produced by three strains in

21 the current study, including serotype O174:H21, which has been previously associated

22 with HUS. Additional virulence factors associated with increased human pathogenicity

23 were determined in five of the nine isolates. The eae gene was identified in two isolates 
1 and serotypes carrying this gene have been linked with severe illness, such as

2 haemorrhagic colitis and HUS (Oswald et al., 2000). The newly identified serotype

3 O63:H- produced VT1 and contained hly and eae genes indicating that this serotype has

4 the potential to be pathogenic to humans. The VTEC strains identified in the present

5 study contain the necessary virulence genes required to cause human disease, and must be

6 considered as potential pathogens that could be involved in future outbreaks of

7 haemorrhagic colitis and HUS. Screening for these and other serotypes should be carried

8 out in suspect clinical cases from which E. coli $\mathrm{O} 157$ is not isolated.

9 E. coli are a rapidly evolving species capable of developing new pathogenic

10 variants (Donnenberg et al., 2001). LeClerc et al., (1996) reported that $1 \%$ of E. coli

11 O157:H7 serotypes had spontaneous rates of mutation that were 1,000 fold higher than

12 those of typical E. coli. This ability to hyper-mutate may lead to the acquisition of

13 virulence genes and development of other properties, such as antibiotic resistance, that

14 increase bacterial diversity thus conferring a competitive advantage. Recently increasing

15 numbers of multi-resistant VTEC have been isolated from humans, cattle and food

16 (vonMüffling et al, 2007, Mora et al., 2005.) The findings of the current study indicate

17 that the VTEC serotypes were simultaneously resistant to several anti-microbial classes,

18 including penicillins, aminoglycosides, tetracyclines, sulphonamides and fluroquinolones

19 with strain O63:H- resistant to 9 antibiotics. Multiple antibiotic resistance may be

20 acquired through mobile genetic elements such as plasmids, transposons and Class 1

21 integrons, (Mora et al., 2005, Singh et al., 2005), or due to the presence of

22 overexpression from chromosomally encoded multi-drug efflux pumps (Poole, 2004). A

23 complete class I integron structure was detected in strain O63:H and the bla-тем gene, 
1 which is generally plasmid encoded, was present in all isolates, suggesting the potential

2 horizontal transfer of antibiotic resistance to other bacteria. Although anti-microbial

3 treatment of VTEC infection is not recommended due to the potential for verotoxin

4 release (Wong et al., 2000) the development of multiple resistant VTEC is nevertheless a

5 development that public health professionals must note. It is unknown whether these AR

6 serotypes have always been present, with a recent increase in prevalance in response to

7 an unknown environmental stimulus. Future work characterizing the potential for

8 resistance transfer from these isolates is critical to ascertain the significance of multiple

9 antibiotic resistance in these pathogens.

10 The identification of rare non-O157, multiply antibiotic resistant VTEC in this

11 study is of concern. Findings from the current study suggest that targeted sampling and

12 method development utilizing the antibiotic resistant characteristics may reveal many

13 more of these serotypes in the bovine population and possibly elsewhere. Antibiotic

14 resistant E. coli are known to be disseminated through the food chain, (Johnson et al.,

15 2005, DeFrancesco et al., 2004) therefore the bacteria from this study may represent a

16 new group of clinically significant food-borne pathogens. This data highlights the need

17 for increased monitoring for the presence of non-O157 VTEC in cattle and humans in

18 addition to monitoring the level of antimicrobial resistance in order to ascertain the

19 potential public health risk of these emerging strains.

\section{References:}


1 1. Altschul, S.F., T.L. Madden, A.A. Schaffer, J. Zhang, Z. Zhang, W. Miller, and

2 D.J. Lipman. 1997. Gapped BLAST and PSI-BLAST: a new generation of 3 protein database search programs. Nucleic Acids Res. 25,3389-3402.

5 2. Batchelor, M., Hopkins K., Threlfall, E.J., Clifton-Hadley, F.A., Stallwood, A.D., 6 Davies, R.H. and Liebana, E. ,2005. blaCTX-M genes in clinical Salmonella 7 isolates recovered from humans in England and Wales from 1992 to 2003, 8 Antimicrob Agents Chemother 49, 1319-1322

9 3. Bauer, A.W., W.M. Kirby, J.C. Sherris, and M. Turck. 1966. Antibiotic 10 susceptibility testing by a standardized single disk method. Am. J. Clin. Pathol. $11 \quad 45,493-496$.

12 4. Beutin, L., D. Geier, S. Zimmermann, S. Aleksic, H.A. Gillespie, and T.S. 13 Whittam. 1997. Epidemiological relatedness and clonal types of natural 14 populations of Escherichia coli strains producing Shiga toxins in separate 15 populations of cattle and sheep. Appl. Environ. Microbiol. 63,2175-2180.

16 5. Blanco, J.E., M. Blanco, M.P. Alonso, A. Mora, G. Dahbi, M.A. Coira, and J. 17 Blanco. 2004a. Serotypes, virulence genes, and intimin types of Shiga toxin 18 (verotoxin)-producing Escherichia coli isolates from human patients: prevalence 19 in Lugo, Spain, from 1992 through 1999. J. Clin. Microbiol. 42, 311-319.

20 6. Blanco, M., J.E. Blanco, A. Mora, G. Dahbi, M.P. Alonso, E.A. Gonzalez, M.I. 21 Bernardez, and J. Blanco. 2004b. Serotypes, virulence genes, and intimin types of 22 Shiga toxin (verotoxin)-producing Escherichia coli isolates from cattle in Spain 
1 and identification of a new intimin variant gene (eae-xi). J. Clin. Microbiol. 42, $2645-651$.

3 7. Boerlin, P., S.A. McEwen, F. Boerlin-Petzold, J.B. Wilson, R.P. Johnson, and 4 C.L. Gyles. 1999. Associations between virulence factors of Shiga toxinproducing Escherichia coli and disease in humans. J. Clin. Microbiol. 37,497-503.

6 8. Crump, J.A., C.R. Braden, M.E. Dey, R.M. Hoekstra, J.M. Rickelman-Apisa, 7 D.A. Baldwin, S.J. De Fijter, S.F. Nowicki, E.M. Koch, T.L. Bannerman, F.W. 8 Smith, J.P. Sarisky, N. Hochberg, and P.S. Mead. 2003. Outbreaks of $9 \quad$ Escherichia coli O157 infections at multiple county agricultural fairs: a hazard of 10 mixing cattle, concession stands and children. Epidemiol. Infect. 131,1055-1062.

11 9. DeFrancesco, K.A., R.N. Cobbold, D.H. Rice, T.E. Besser, and D.D. Hancock. 12 2004. Antimicrobial resistance of commensal Escherichia coli from dairy cattle associated with recent multi-resistant salmonellosis outbreaks. Vet. Microbiol. 98, $55-61$.

10. Donnenberg M.S. and Whittam, T.W., 2001. Pathogenesis and evolution of virulence in enteropathogenic and enterohemorrhagic Escherichia coli. Journal of Clin Investigation, 107, 539-548.

11. Elder, R.O., J.E. Keen, G.R. Siragusa, G.A. Barkocy-Gallagher, M. Koohmaraie, and W.W. Laegreid. 2000. Correlation of enterohemorrhagic Escherichia coli O157 prevalence in feces, hides, and carcasses of beef cattle during processing. Proc. Natl. Acad. Sci. U S A. 97,2999-3003. 
1 12. EU-REPORT, 2001 EU-REPORT, 2001. Report on VT E. coli - trends and

2 sources of zoonotic agents in European Union and Norway. 237, chapter 11.

3 http://europa.eu.int/comm/food/fs/sfp/mr/rep2001/11_ecoli_2001.pdf

4 13. Frankel, G., A.D. Phillips, I. Rosenshine, G. Dougan, J.B. Kaper, and S. Knutton.

5 1998. Enteropathogenic and enterohaemorrhagic Escherichia coli: more $6 \quad$ subversive elements. Mol. Microbiol. 30,911-921.

7 14. Fratamico, P.M., L.K. Bagi, and T. Pepe. 2000. A multiplex polymerase chain 8 reaction assay for rapid detection and identification of Escherichia coli O157:H7

$9 \quad$ in foods and bovine feces. J. Food Prot. 63,1032-1037.

10 15. Griffin, P.M. and R.V. Tauxe. 1991. The epidemiology of infections caused by 11 Escherichia coli O157:H7, other enterohemorrhagic E. coli, and the associated 12 hemolytic uremic syndrome. Epidemiol. Rev. 13,60-98.

13 16. Guinée, P. A. M., W. H. Jansen, T. Wadström, and R. Sellwood. 1981. Escherichia coli 14 associated with neonatal diarrhoea in piglets and calves. Curr. Top. Vet. Anim. Sci. $15 \quad 13,126-162$.

16 17. Henriques, I.S., Fonseca, F., Alves, A., Saavedra, M-J and Correia, A. (2006)

17 Occurrence and diversity of integrons and $\beta$-lactamase genes among ampicillin-resistant 18 isolates from estuarine waters. Res Microbiology, 10, 938-947

19 18. Howie, H., A. Mukerjee, J. Cowden, J. Leith, and T. Reid. 2003. Investigation of 20 an outbreak of Escherichia coli $\mathrm{O} 157$ infection caused by environmental exposure $21 \quad$ at a scout camp. Epidemiol. Infect. 131,1063-1069.

22 19. Iguchi, A., R. Osawa, J. Kawano, A. Shimizu, J. Terajima, and H. Watanabe. 23 2002. Effects of repeated subculturing and prolonged storage at room 
temperature of enterohemorrhagic Escherichia coli $\mathrm{O} 157: \mathrm{H} 7$ on pulsed-field gel electrophoresis profiles. J. Clin. Microbiol. 40,3079-3081.

20. Johnson, J.R., M.A. Kuskowski, K. Smith, T.T. O'Bryan, and S. Tatini. 2005. Antimicrobial-resistant and extraintestinal pathogenic Escherichia coli in retail foods. J. Infect. Dis. 191,1040-1049.

21. Kobayashi, H., J. Shimada, M. Nakazawa, T. Morozumi, T. Pohjanvirta, S. Pelkonen, and K. Yamamoto. 2001. Prevalence and characteristics of shiga toxinproducing Escherichia coli from healthy cattle in Japan. Appl. Environ. Microbiol. 67,484-489.

22. LeClerc, J.E., B. Li, W.L. Payne, and T.A. Cebula. 1996. High mutation frequencies among Escherichia coli and Salmonella pathogens. Science. 274,1208-1211.

23. Mora, A., M. Blanco, J.E. Blanco, M.P. Alonso, G. Dhabi, F. Thomson-Carter, M.A. Usera, R. Bartolome, G. Prats, and J. Blanco. 2004. Phage types and genotypes of shiga toxin-producing Escherichia coli O157:H7 isolates from humans and animals in spain: identification and characterization of two predominating phage types (PT2 and PT8). J. Clin. Microbiol. 42, 4007-4015.

24. Mora, A., J.E. Blanco, M. Blanco, M.P. Alonso, G. Dhabi, A. Echeita, E.A. Gonzalez, M.I. Bernardez, and J. Blanco. 2005. Antimicrobial resistance of Shiga toxin (verotoxin)-producing Escherichia coli $\mathrm{O} 157: \mathrm{H} 7$ and non-O157 strains isolated from humans, cattle, sheep and food in Spain. Res. Microbiol. 156,793806. 
1 25. Moxon, E.R., P.B. Rainey, M.A. Nowak, and R.E. Lenski. 1994. Adaptive

2 evolution of highly mutable loci in pathogenic bacteria. Curr. Biol. 4,24 -33.

3 26. Murase, T., S. Yamai, and H. Watanabe. 1999. Changes in pulsed-field gel

4 electrophoresis patterns in clinical isolates of enterohemorrhagic Escherichia coli

5 O157:H7 associated with loss of Shiga toxin genes. Curr. Microbiol. 38,48-50.

6 27. National Committee for Clinical Laboratory Standards. 2003. Performance

$7 \quad$ Standards for Antimicrobial Susceptibility Testing; $14^{\text {th }}$ ed. NCCLS M100-S14.

8 National Committee for Clinical Laboratory Standards, Wayne, Pa.

9 28. O'Mahony, R., Saugy, M., Leonard, N., Drudy, D., Bradshaw, B., Egan, J.,

10 Whyte,P., O'Mahony, M., Wall, P. and Fanning, S. (2005) Antimicrobial

11 resistance in isolates of Salmonella spp. from pigs and the characterisation of a

12 S. Infantis gene cassette. Foodborne Pathogens and Disease, 2, 274-278.

13 29. Ostroff, S.M., P.I. Tarr, M.A. Neill, J.H. Lewis, N. Hargrett-Bean, and J.M.

14 Kobayashi. 1989. Toxin genotypes and plasmid profiles as determinants of

15 systemic sequelae in Escherichia coli O157:H7 infections. J. Infect. Dis. 160,994-

16998.

17 30. Oswald, E., H. Schmidt, S. Morabito, H. Karch, O. Marches, and A. Caprioli.

18 2000. Typing of intimin genes in human and animal enterohemorrhagic and

19 enteropathogenic Escherichia coli: characterization of a new intimin variant.

20 Infect. Immun. 68,64-71.

21 31. Paton, A.W. and J.C. Paton. 1998. Detection and characterization of Shiga

22 toxigenic Escherichia coli by using multiplex PCR assays for stxl, stx2, eaeA, 
1 enterohemorrhagic E. coli hlyA, rfbO111, and $r f b \mathrm{O} 157$. J. Clin. Microbiol. $2 \quad 36,598-602$.

3 32. Pomba C, Mendonça N, Costa M, Louro D, Baptista B, Ferreira M, Correia JD, 4 Caniça M. (2006) Improved multiplex PCR method for the rapid detection of 5 beta-lactamase genes in Escherichia coli of animal origin. Diagn Microbiol Infect 6 Dis. $56,103-106$.

7 33. Poole, K. 2004. Efflux-mediated multiresistance in Gram-negative bacteria. $8 \quad$ Clin.Microbiol. Inf.10,12-26.

9 34. SANCO, 2001 SANCO, Staff Paper on the Results of a Series of Missions to 10 Review the Operation of Controls over Verotoxygenic Escherichia coli in the 11 Food Production Sector with Particular Reference to Red Meat, Meat Products 12 and Milk/Milk Products. European Commission, Food and Veterinary Office 13 (2001).

14 35. Singh, R., C.M. Schroeder, J. Meng, D.G. White, P.F. McDermott, D.D. Wagner, 15 H. Yang, S. Simjee, C. Debroy, R.D. Walker, and S. Zhao. 2005. Identification of 16 antimicrobial resistance and class 1 integrons in Shiga toxin-producing 17 Escherichia coli recovered from humans and food animals. J. Antimicrob. 18 Chemother. 56,216-219.

19 36. Thompson, J.D., Higgins, D.G. \& Gibson, T.G. (1994) CLUSTALW: improving 20 the sensitivity of progressive multiple sequence alignment through sequence 21 weighting, positions specific gap penalties and weight matrix choice. Nucleic 22 Acids Research, 22, 4673-80. 
1 37. vonMüffling, T., M. Smaijolvic, B. Nowak, K. Sammat, Bülte, M. and G. Klein.

2 Preliminary study of certain serotypes, genetic and antimicrobial resistance

3 profiles of verotoxigenic Escherichia coli (VTEC) isolated in Bosnia and

4 Germany from cattle or pigs and their products. 2007. Int J Food Micro .117, 185-

591

6 38. Wichard J (2005) Beta lactam resistance and enterobacteriaceae, United States.

$7 \quad$ Emerg Infect Dis 11, 1464-1466

8 39. Wong, C.S., S. Jelacic, R.L. Habeeb, S.L. Watkins, and P.I. Tarr. 2000. The risk

9 of the hemolytic-uremic syndrome after antibiotic treatment of Escherichia coli

$10 \quad$ O157:H7 infections. N. Engl. J. Med. 342,1930-1936.

11

12

13

14

15

16

17

18 
